NASA/TM-2000-210382

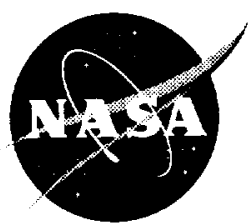

\title{
Plume and Discharge Plasma Measurements of an NSTAR-type Ion Thruster
}

John E. Foster, George C. Soulas, and Michael J. Patterson

Glenn Research Center, Cleveland, Ohio

Prepared for the

36th Joint Propulsion Conference and Exhibit

sponsored by the American Institute of Aeronautics and Astronautics

Huntsville, Alabama, July 16-19, 2000

National Aeronautics and

Space Administration

Glenn Research Center 
Available from

NASA Center for Aerospace Information

7121 Standard Drive

Hanover, MD 21076

Price Code: A03
National Technical Information Service 5285 Port Royal Road Springfield, VA 22100 Price Code: A03

Available electronically at http://gltrs.grc.nasa.gov/GLTRS 


\title{
Plume and Discharge Plasma Measurements of an NSTAR-type Ion Thruster
}

\author{
John E. Foster, George C. Soulas, and Michael J. Patterson \\ National Aeronautics and Space Administration \\ Glenn Research Center \\ Cleveland, Ohio 44135
}

The success of the NASA Deep Space 1 spacecraft has demonstrated that ion propulsion is a viable option for deep space science missions. More aggressive missions such as Comet Nuclear Sample Return and Europa lander will require higher power, higher propellant throughput and longer thruster lifetime than the NASA Solar Electric Propulsion Technology Application Readiness (NSTAR) engine. Presented here are thruster plume and discharge plasma measurements of an NSTAR-type thruster operated from $0.5 \mathrm{~kW}$ to $5 \mathrm{~kW}$. From Faraday plume sweeps, beam divergence was determined. From Langmuir probe plume measurements on centerline, low energy ion production on axis due to charge-exchange and direct ionization was assessed. Additionally, plume plasma potential measurements made on axis were used to determine the upper energy limits at which ions created on centerline could be radially accelerated. Wall probes flushmounted to the thruster discharge chamber anode were used to assess plasma conditions. Langmuir probe measurements at the wall indicated significant differences in the electron temperature in the cylindrical and conical sections of the discharge chamber.

\section{Nomenclature}

$$
\begin{aligned}
& e=\text { Elementary charge of an electron } \\
& E=\text { Electron energy } \\
& E_{\text {beam }}=\text { Beam ion energy } \\
& f(r, z)=\text { Fraction of total integrated beam } \\
& \text { current } \\
& I=\text { Ionization energy of xenon } \\
& I_{b e a m}=\text { Ion beam current } \\
& I_{c}=\text { Ion Current to the cathode } \\
& I_{d}=\text { Discharge current } \\
& I_{i o n}=\text { Total ion current } \\
& I_{s i r e e n}=\text { Ion current collected to screen } \\
& I_{s h e l l}=\text { grid surfaces } \\
& j_{b}=\text { Beam current to anode surfaces between } \\
& k=\text { Boltzmann's constant } \\
& M_{X e}=\text { Mass of xenon atom } \\
& n_{e}=\text { Electron number density } \\
& n_{i}=\text { Ion number density } \\
& n_{o}=\text { Neutral number density } \\
& r=\text { Radial location }
\end{aligned}
$$

$r_{c e x}=$ Charge exchange production rate

$r_{i}=$ Ion production rate via electron bombardment

$s_{f}=$ Slope of total beam current fraction

$T_{\mathcal{e}}=$ Electron temperature

$V_{d}=$ Discharge voltage

$V_{p}=$ Plasma potential relative to neutralizer common

$\beta_{f}=$ Beam divergence half-angle

$z=$ Axial location

$\varepsilon_{p}=$ Discharge ion production cost

$v=$ Bohm Velocity

$v_{\text {beam }}=$ Beam ion velocity

$\sigma_{c c x}=$ Charge exchange cross section

$\sigma_{n e}=$ Electron neutral ionization cross section

\section{Introduction}

The recent success of the NASA Solar Electric Propulsion Technology Application Readiness (NSTAR) program which provided the propulsion system for the Deep Space I (DS1) spacecraft demonstrates the utility and viability of ion thrusters for deep space science missions. The NSTAR thruster satisfied the mission requirements by successfully providing the necessary delta-v to 
enable the DSI spacecraft to fly by the asteroid Braille.' For more energetic missions such as Comet Nuclear Sample Return (CNSR), Neptune Orbiter, and Europa Lander, power requirements are likely to exceed that of the NSTAR thruster (i.e. $2.3 \mathrm{~kW}$ maximum) for the initial outwardbound stage of the mission. These power requirements are expected to reach $5 \mathrm{~kW}$ per thruster.

In order to develop a foundation for achieving these requirements, an investigation was initiated that focused on characterizing the ion beam and discharge plasma of an NSTAR-type thruster up to $5 \mathrm{~kW}$ in order to investigate the operating limitations of this design and to obtain insight into what design modifications may be necessary to realize a $5 \mathrm{~kW}$ thruster. Plume studies at power levels up to $5 \mathrm{~kW}$ provide insight into plume behavior such as beam divergence and radial ion flux production in the beam, all of which are important from a spacecraft-thruster plume interaction standpoint. Discharge chamber plasma properties measured at the elevated power levels provide useful insight into how plasma loss mechanisms impact discharge.

NSTAR thruster operation has been characterized over the range of NSTAR thruster operating conditions in past studies. ${ }^{23}$ In these studies, the thruster plume surveys were acquired at a fixed axial position. Furthermore, discharge plasma properties were not measured.

In the work presented here, a thruster of configuration similar to that of the NSTAR thruster was performance-tested up to $5 \mathrm{~kW}$ and the discharge plasma and thruster plume were documented. This investigation included acquiring Faraday sweeps at different axial locations so that beam divergence as a function of thruster input power could be determined. Quantifying beam divergence is particularly important in that it directly addresses spacecraft-thruster plume interaction concerns at the higher power levels. Detailed Faraday probe measurements in the plume may also be found elsewhere. ${ }^{4}$ Additionally, the plume plasma potential, electron temperature, and electron number density was characterized on axis using a Langmuir probe. These measurements were used to determine the production rate and radial energy of low energy ions generated on axis as a function of thruster input power so that their effect on spacecraft surfaces could be assessed. The discharge chamber plasma was investigated using planar Langmuir probes flush mounted to the anode. The probes were used to estimate ion and electron losses to anode surface area between cusps for quantifying discharge efficiency and thermal transport to the anode as a function of thruster power.

\section{Experimental Set-up}

Thruster testing took place at the NASA Glenn Research Center Vacuum Facility 11. A photograph of the facility is shown in Figure 1. The aluminum facility is approximately $2.2 \mathrm{~m}$ in diameter and $7.9 \mathrm{~m}$ in length. The pumping train includes a two-stage blower system backed by a roughing pump, a turbomolcular pump, and seven helium cryopumps. The approximate pumping speed was $110,000 \mathrm{l} / \mathrm{s}$ on xenon at $1 \times 10^{-6}$ Torr. The nominal base pressure was $1.3 \times 10^{-5} \mathrm{~Pa}(1 \mathrm{x}$ $10^{-7}$ Torr) while background pressure at the highest thruster power condition investigated $(4.6 \mathrm{~kW})$ was $6.6 \times 10^{-4} \mathrm{~Pa}\left(4.9 \times 10^{-6}\right.$ Torr $)$.

A schematic of the ion thruster and internal discharge chamber wall probes is illustrated in Figure. 2. Additional details regarding the $30-\mathrm{cm}$ engine, the power console, and the xenon feed system can be found elsewhere..$^{4-6}$ The discharge chamber consisted of a conical section and a downstream cylindrical section. The magnetic circuit consisted of three permanent magnet rings: 1) the cathode ring. located at the backplate of the conical section; 2) the cylindrical section ring. located at the junction between the cylindrical section and the conical section; and 3) the pole piece ring, located at the most downstream flange of the cylindrical section.

The four planar molybdenum wall probes each measured $6.4 \mathrm{~mm}$ in diameter. The wall probes were flush mounted with the surface of the anode at positions indicated in Figure 2. The probes were designated according to number as indicated in Figure 2. The probes were electrically isolated from the anode wall and were held in place using modified compression fittings. Probes \#1 and \#3, which are located near cusps, were not used in this investigation. Data used in this paper were collected at wall probes $\# 2$ and \#4. These probes were used because they are located near the midpoints between the cathode and cylinder cusps and the cylinder and pole piece cusps respectively. Midway between any two cusps, the magnetic field strength is minimum. The transverse diffusion is therefore greatest at these locations. In this respect, the current measured at this location can be used to estimate an upper limit to electron flux collected between the cusps.

The transverse magnetic field component across the surface of wall probes $\# 2$ and \#4 was approximately $25 \mathrm{G}$. The wall probes were biased relative to cathode potential using a variable 
DC voltage source to obtain Langmuir currentvoltage characteristics.

The thruster plume was interrogated using a Faraday probe and a cylindrical Langmuir probe. The Faraday probe consisted of a $1 \mathrm{~cm}^{2}$ molybdenum disk. The probe was biased about 30 volts below ground to repel plume electrons. The current collected at the probe passed through a $1000 \Omega$ resistor. The cylindrical Langmuir probe, which was also made of molybdenum, was $1.3 \mathrm{~mm}$ in diameter and $8 \mathrm{~mm}$ in length. The probe length was oriented perpendicular to the thruster axis. Probe current-voltage characteristics were acquired and analyzed using commercially-available hardware and software.

The Langmuir and Faraday probes' positions could be varied with respect to the engine using an $r-z$ translation system. The positioning system allowed for continuous sweeps across the thruster plume at speeds up to $6.6 \mathrm{~m} / \mathrm{min}$. The positioning system allowed the probe to be moved radially across the plume $\pm 0.625 \mathrm{~m}$ with respect to the geometric center of the optics and axially $1.25 \mathrm{~m}$ downstream of the optics. The probes were positioned such that they passed across the diameter of the engine during a sweep.

\section{Results and Discussion}

An ion thruster generates primarily two types of plasma: the flowing plasma that makes up the ion beam and the discharge chamber plasma. Accordingly, this work is divided into a thruster plume and a discharge plasma analysis.

The plume and discharge plasma were investigated as a function of thruster input power between 0.5 and $4.6 \mathrm{~kW}$. All thruster operating conditions are listed in Table $\mathrm{I}$.

\section{Plume Measurements}

\section{Faradav Probe Surveys}

Typical Faraday probe sweeps are illustrated in Figure 3. The measurements were integrated to determine a beam current. The integration method assumes azimuthal symmetry. The integrated beam currents were typically 10 to $15 \%$ higher than the measured beam current. The assumption of azimuthal symmetry was likely a source of error in integrated beam currents. Although, the acquired Faraday data was not corrected for secondary electrons, the uncertainty associated with secondary electrons ejected from the probe due to singly charged ions bombardment was calculated to be less than $2 \%{ }^{8}$ Additional error may be attributed to the collection of charge-exchange ions. The lower limit of uncertainty in collected current due to charge-exchange was estimated from Langmuir probe measurements to range between 3 and $5 \%$. This estimate was based on the a priori assumption that the charge-exchange ion density was less than or equal to the beam ion density. Past findings suggest that the charge-exchange ion density on centerline is considerably smaller than the primary beam ion density thereby supporting this assumption. ${ }^{9}$ Additional error in the Faraday probe measurements is attributed to uncertainty in the probe surface area and over-sampling.

Plume profiles at the closest approach $(49 \mathrm{~mm})$, which are presented in Figure 3, illustrate the variations in the beam radial profile as a function of throttle condition. As shown in this figure, the total beam width does not vary appreciably with thruster power. The ratio of the average beam current density to the peak beam current density (i.e. flatness parameter) varied from about 0.45 at $1.4 \mathrm{~kW}$ to about 0.51 at $2.3 \mathrm{~kW}$. The increase is due to the formation of a less peaked beam profile as discharge power increased.

Figures 4 - 7 catalog the variations in the plume profile as a function of axial distance downstream of the thruster at four thruster input powers: 0.5 , $1.4,2.3$, and $3.0 \mathrm{~kW}$. It was found that the peak current density dropped off exponentially with increasing axial distance from the optics. This exponential drop-off is due to beam divergence and to a lesser extent, charge-exchange ion production. From curve fits of the axial variation in the peak current density, the exponential decay rate factor could be determined. The rate factor is a measure of the distance over which the peak beam current density drops by $37 \%$. The rate factor decreased from $654 \mathrm{~mm}$ at the $0.5 \mathrm{~kW}$ condition to $300 \mathrm{~mm}$ at $3.0 \mathrm{~kW}$. The decrease in the rate factor may be attributed to in part due to an increase in chargeexchange collisions as the tank pressure increases with increasing thruster power. Tank pressure increased by a factor of 2 as thruster power increased from the $0.5 \mathrm{~kW}$ condition to the $3.0 \mathrm{~kW}$ condition.

From the Faraday current density profiles, beam divergence half-angle as a function of percent of enclosed beam current was determined. The divergence half-angle was determined by first calculating the enclosed current fraction as a function of radial position at different axial locations. At each axial location, the fraction of total integrated beam current as a function of radius was determined by: 


$$
f(r, z)=\frac{\int_{0}^{r} j_{b}(r, z) \cdot r \cdot d r}{\int_{0}^{\infty} j_{b}(r, z) \cdot r \cdot d r} .
$$

Next, plots of constant enclosed current-fraction as a function of radial location were generated. Since these fractions were linear, linear regression could be used to determine slope of each fraction. The divergence half-angle could then be determined from the slope using the following equation:

$$
\beta_{f}=\arctan \left(\frac{1}{s_{f}}\right) \text {. }
$$

From these values, plots of percentage of total beam current as a function of divergence half-angle were generated. Figure 8 illustrates the variations in divergence angle at three different throttle condition. The divergence half-angle does not vary appreciably with thruster power. As can be seen in the figure, a $25^{\circ}$ half-angle includes more than $90 \%$ of the beam current for the conditions shown.

\section{Langmuir Probe Measurements}

A cylindrical Langmuir probe was used to obtain plasma conditions in the thruster plume on centerline of the optics at a number of throttle conditions. From the Langmuir probe measurements in the plume, ion saturation currents. electron temperatures and plasma potentials were determined. Figure 9 illustrates the variations in plasma potential as a function of position and throttle condition. As shown in the figure, the plasma potential gradually dropped off with increasing axial distance from the thruster. With the exception of the $1.7 \mathrm{~kW}$ case, the plasma potential on centerline at a given axial location tended to decrease with increasing thruster power. This reduction is related to the measured drop in electron temperature which also decreased with increasing thruster power. The discrepancy in the plasma potential trend at the $1.7 \mathrm{~kW}$ operating condition is associated with neutralizer operation. At the $1.7 \mathrm{~kW}$ operating condition, the neutralizer keeper voltage was 1 volt higher than the $1.4 \mathrm{~kW}$ condition and approximately 2 volts higher than the 2.3. 3.0 and $4.6 \mathrm{~kW}$ operating conditions. The higher keeper voltage gives rise to a larger electron temperature at $1.7 \mathrm{~kW}$ as indicated in Figure 10.

Low energy ions are produced in the beam via charge-exchange and to a lesser extent, by electron bombardment of the background gas. The production rate of these ions is highest on centerline because plasma density is greatest there. The centerline plasma potential measured with respect to neutralizer common could be used to ascertain the maximum radial energy that these ions born on centerline can obtain as they exit the beam and strike spacecraft structures. Ions created near the centerline of the optics have a radial energy component equal to $e \cdot V_{p}$ once they exit the plume. The energy of such ions is particularly important to spacecraft designers because these ions can sputter erode the spacecraft if the plasma potential on centerline is sufficiently high. The plasma potential measurements taken in this work were measured with respect to tank ground. In space, spacecraft ground is tied to neutralizer common. In this respect, the neutralizer coupling voltage must be subtracted from the plasma potential measurements presented in Figure 9 to ascertain the energy of the radially accelerated ions. The neutralizer coupling voltage with respect to ground varied from -14 volts at the $0.5 \mathrm{~kW}$ condition to approximately -16 volts at the $4.6 \mathrm{~kW}$ operating condition. Taking this correction into account, ions born on axis would impact spacecraft structures with energies at about the sputtering threshold of metals such as titanium (18 $\mathrm{eV})$. aluminum $(18 \mathrm{eV})$, and iron $(22 \mathrm{eV}) .^{10}$ In order to minimize these effects care must be taken to keep the neutralizer coupling voltage sufficiently low.

Variations in electron temperature as a function of axial position and throttle condition are illustrated in Figure 10. The electron temperature did not vary significantly as a function of axial position for the portion of the plume investigated in this work. The electron temperature did appear to decrease with increasing thruster power. This behavior is attributed to reductions in both the neutralizer keeper voltage and the absolute value of the coupling voltage.

Langmuir probe electron temperature measurements taken inside the thruster plume can provide useful insight into the production of the low energy ions on centerline. The chargeexchange production rate was compared to direct electron-impact ionization to determine under which conditions is direct electron impact ionization a significant producer of low energy ions.

The charge-exchange ion production rate may be calculated directly from background pressure and the beam ion density:

$$
r_{c e x}=\int_{0}^{\infty} n_{o} \cdot n_{i} \cdot \sigma_{c e x}(E) \cdot \sqrt{\frac{2 E}{M_{X e}}} \cdot d E
$$


Because the ion beam is essentially monoenergtic, the integral disappears and the charge exchange production rate becomes:

$$
r_{c e x}=n_{o} \cdot n_{i} \cdot \sigma_{\text {cex }}\left(E_{\text {beani }}\right) \cdot v_{\text {beam }}
$$

Similarly the direct ionization ion production rate may be expressed as:

$$
r_{i}=\int_{I}^{\infty} n_{o} \cdot n_{e} \cdot \sigma_{n e}(E) \cdot \sqrt{\frac{2 E}{M_{X e}}} \cdot d E
$$

Here, I is the ionization threshold for xenon, 12.1 $\mathrm{eV}$. In this case, the electron population in the plume was assumed to be Maxwellian. Langmuir probe data confirmed this assumption. Cross section data for the charge-exchange and for direct ionization were obtained from references 11 and 12 , respectively.

Because both the charge-exchange production rate and the direct ionization rate are proportional to the background neutral density, the ratio of the ion production rates to first order is independent of background pressure. Figure 11 illustrates the variations in the ratio of the direct ionization rate to the charge-exchange ion production rate in the thruster plume at $49 \mathrm{~mm}$ downstream of the engine as a function of thruster power. Charge-exchange ion production is dominant under all conditions

Ionization of the background gas due to direct electron impact is very sensitive to electron temperature. Poor coupling voltage or high keeper voltages would tend to increase the electron temperature. Modest increases in the electron temperature can give rise to large changes in the ionization rate. For example, a $0.5 \mathrm{eV}$ increase in the electron temperature would give rise to an order of magnitude increase in the ionization rate at fixed background pressure. Because these low energy ions contribute to grid erosion. care must always be taken to minimize the contribution to low energy ion production by direct electron impact by minimizing the neutralizer keeper voltage and the magnitude of the neutralizer coupling voltage.

\section{Discharge Chamber Measurements}

Ideally, electron collection in a ring-cusp thruster should occur solely at the magnetic cusps. In practice, electrons and ions are also lost to the anode between cusps. This loss can be attributed to a weak magnetic containment field between cusps (i.e. low Hall parameter) and to discharge instabilities. Two planar wall probes (i.e. probes $\# 2$ and \#4) located between the anode cusps (see
Fig. 2) were used measure the plasma properties and wall losses at the anode. The potential of each probe was varied with respect to the cathode to determine electron saturation current, ion saturation current, and electron energetics. From the electron and ion saturation current densities measured at the probes, the electron and ion currents incident on the anode between the cusps could be estimated. The electron-retarding region of the current-voltage characteristic of the wall probes can be used to ascertain whether the electron population at the anode wall was Maxwellian or if there were primary electrons reaching the wall between the cusps.

The weak fields located at probes \#2 and \#4 (about $25 \mathrm{G}$ ) made them ideal locations to make near-anode plasma measurements. Because ion motion is not significantly influenced at these weak field strengths, the ion saturation current measured at the probe should not appreciably differ from the unmagnetized case. The estimated accuracy of the ion density as determined from the ion saturation current and the electron temperature was $35 \%$. Because the ratio of the Debye length to the electron Larmor radius is less than unity, electrons in the sheath at the probe were not magnetized. Consequently, usual analysis of the electron temperature should be applicable provided points in the retarding region are sufficiently far from the plasma potential. The estimated error in the electron temperature was about $15 \%$.

\section{Estimated Electron Current Lost between} Cusps

The electron current collected by the anode between the cathode cusp and the middle anode cusp was estimated by wall probe \#2. The electron current collected by the anode shell between the middle anode cusp and the pole piece cusp was estimated by wall probe \#4. Again, these probes were chosen because of their near proximity to the midpoint between the cusps. As can be seen in Figure 12, the electron saturation current increases monotonically with increasing discharge power. This increase is a consequence of the nearly linear increase in plasma density (shown in Figure 13) as determined from the ion saturation current as the discharge power increases. For all discharge powers, the electron current density at the wall was highest at the wall probe in the cylindrical section (wall probe \# 4).

Current densities determined at the wall probes were multiplied by the associated surface areas between the cusps to estimate the electron current collected in that region. The current for each region was then summed to estimate the total 
electron current collected at the anode shell between the cusps. The transverse magnetic field component between any two cusps is weakest midway between the cusps. Because wall probes \#2 and \#4 are located near the midpoint between cusps, the calculated electron current collected between cusps as determined by this procedure represents an upper limit. A plot of the estimated total electron current collected at the wall between cusps is plotted as a function of discharge power in Figure 14. The plot indicates that a significant fraction (i.e. $\sim 30 \%$ ) of the discharge current can be collected at the anode shell. As can be seen in the figure, the ratio of the collected electron current to the cathode emission current is constant. This constancy indicates that the electron current to the walls is simply proportional to the cathode emission current. Because discharge losses decrease with increasing thruster power (240 to $170 \mathrm{~W} / \mathrm{A}$ from 0.5 to $2.3 \mathrm{~kW}$ ), the electron flux to the walls may not necessarily represent a problem with magnetic containment. Indeed, as long as the electrons lost to the walls are low energy thermals, then ionization efficiency is not compromised. The fact that the electrons collected at the walls had a Maxwellian distribution is confirmed by electron temperature measurements.

It is noteworthy that the electron current collected between cusps was highest in the cylindrical section. Even though the cylindrical section surface area was only $9 \%$ larger than the conical section of the discharge chamber, the estimated electron current to the cylindrical section was on average $50-60 \%$ higher than that collected in the conical section.

\section{Ion Losses to the Anode Shell and Screen} Grid

In general, it is desirable to maximize the ratio of ion beam current to the total ion current produced in the discharge chamber. Because of the reduced magnetic field between the cusps, ion containment between the cusps is not significant. Though ion containment is not significant, past studies have shown that the ion flow to anode surfaces is not isotropic. ${ }^{13-15}$ In order to assess how the ratio of ion beam current to the total ion current produced in the discharge chamber varied with discharge power, the ion saturation current density was measured at wall probes \#2 and \#4. Following a procedure similar to that described previously, the ion current density was multiplied by the associated surface area to determine the ion current. It should be pointed out that ion current collected at the anode cusps can be significant. ${ }^{16}$ Because this calculation does not take into account the ion current collected at the cusps, it represents an approximation of the lower limit of the ion current at the anode.

Figure 15 illustrates variations in the estimated ion current collected at the anode and screen grid as well as the ratio of ion beam current to the total ion production current as a function of discharge power. The total ion production current is defined as follows:

$$
I_{\text {ion }_{t, 1}}=I_{\text {shell }}+I_{\text {screen }}+I_{\text {beam }}+I_{c}
$$

Ion current collected at the cathode is neglected in this relation. The screen grid ion current was determined by biasing the screen grid $20 \mathrm{~V}$ below the cathode potential. As shown in Figure 15, the ratio of beam current to the total discharge ion production current is constant. Even though the open area fraction of the ion optics is considerably smaller than the surface area of the discharge chamber, some $44 \%$ of the ions produced in the discharge are extracted. The magnitude of this extraction fraction is consistent with previous studies ${ }^{13-15}$ and also suggests non-isotropic flow of ions to the extraction optics.

A rough determination of discharge ion production costs can be calculated from the relation:

$$
\varepsilon_{p}=\frac{I_{d} \cdot V_{d}}{I_{i n_{i, \tau}}}
$$

The discharge ion production cost is a measure of the energy required to produce an ion in the discharge chamber. It includes those processes associated with hollow cathode operation, electronneutral and electron-ion interactions, and collection of thermal electrons at the anode. Figure 16 illustrates the behavior of this parameter as well as beam ion production costs as a function of discharge propellant utilization efficiency. The value of the discharge ion production cost drops from $100 \mathrm{~W} / \mathrm{A}$ at the lowest discharge propellant efficiency investigated (i.e. that at $0.5 \mathrm{~kW}$ ) to roughly $70 \mathrm{~W} / \mathrm{A}$ at the highest discharge propellant efficiency investigated (i.e. that at $3.0 \mathrm{~kW}$ ). Variations of this parameter follow variations in the ion beam production cost.

Compared to the conical section of the discharge chamber, cylindrical section collected a larger fraction of the total ion current. As total thruster power ranged from $0.5 \mathrm{~kW}$ to the $5 \mathrm{~kW}$ condition, the cylindrical section collected $70 \%$ to $50 \%$, respectively more ion current than the conical 
section of the discharge chamber. This finding also suggests that a significant portion of the plasma production is occurring in the cylindrical section. This localization is desirable from an ion extraction standpoint due to the proximity of the ion optics.

\section{Electron Energetics}

Figure 17 illustrates the behavior of the electron temperature as a function of discharge power. For all cases, the electron temperature was roughly 3 $\mathrm{eV}$ higher in the cylindrical section as compared to the conical section of the thruster. These data suggest that the energy exchange between the primary electrons and the plasma is more efficient in the cylindrical section thereby yielding a higher temperature there.

Primary electrons interact via collisions with thermal electrons to raise the overall effective electron temperature in the cylindrical section. Primary electrons emanating from the discharge cathode on axis have very long mean free paths (i.e. greater than $1 \mathrm{~m}$ ). The fact that the primary electrons are highly directional and localized to the axis has been documented. ${ }^{17}$ Because the probability of these electrons interacting with the background plasma increases with increasing pathlength from the cathode, the likelihood of thermalization is higher in the most downstream section (i.e. the cylindrical section) of the discharge chamber. Additionally, because of the directional nature of the primary electrons, backscattering of these electrons toward conical-section anode surfaces requires significant scattering. The primary electrons that do reach the walls in the conical section can be expected to be much cooler.

It should be pointed that this low mixing of primary electrons with background electrons in the conical section is consistent with the findings of reference 17 . In that study, it was found that the primary electron population on centerline is quite directional and distinct near the cathode but smears out in energy with increasing axial distance becoming Maxwellian-like with an elongated tail near the exit plane of the thruster. This elongated tail gives rise to a higher effective electron temperature.

Better primary electron containment and utilization in the cylindrical section may also be attributed to the cathode-biased screen grid which terminates the most downstream plane of the cylindrical section. The negative potential of the screen reflects some the primary electrons back into the discharge. Because these electrons must turn around at this boundary, their residence time in the cylindrical section is enhanced, thereby increasing the probability of a collision. Diffusion of the reflected primary electrons toward the conical section is reduced by the magnetic field gradient that increases in this direction (see Figure 18 for variation in axial component of discharge chamber magnetic field). Lack of penetration of these energetic electrons into the conical region due to the magnetic field would also lead to reduced mixing in this region. The primary electrons reflected at the screen grid would then tend to be confined locally in a volume just upstream of the screen grid and would therefore thermalize with electrons in this region. This heating in the cylindrical section would give rise to a larger average electron temperature relative to that of the conical section.

The larger electron temperature in the cylindrical section should lead to a larger plasma density there. However, the plasma density measured at the wall in the conical section as shown in Figure 13 was roughly equal to that measured in the cylindrical section within the experimental uncertainty. It is somewhat surprising that the ion density at the wall was not significantly higher in the cylindrical section as compared to that measured in the conical section. The plasma in the conical section may have benefited from near-cathode ionization processes whereas the cylindrical section plasma may depend more on primary electron ionization processes. This notion is also consistent with the observed higher electron temperature in the cylindrical section. It is desirable, however, to have the hottest plasma just upstream of the ion optics because it assures that this energy will be used to generate ions that have a higher probability of reaching the extraction optics rather than recombining at the anode walls.

As pointed out earlier, the ion and electron current density was significantly higher in the cylindrical section than in the conical region even though plasma densities in these regions were similar. This observation is now readily explainable. In general, the electron temperature determines in part the rate at which plasma diffuses from the central portion of the discharge. Ions diffuse toward the wall at the Bohm velocity:

$$
v=\sqrt{\frac{k \cdot T_{e}}{M_{X e}}}
$$

The electron saturation current is also proportional to the square root of the electron temperature. Because the plasma density in both regions of the discharge chamber is roughly equal, the flux to the walls will be highest in the cylindrical section because the electron temperature is highest in this 
region. In this respect, the ion and electron loss rate to the walls is highest in the cylindrical section. The plasma production rate must be correspondingly higher in the cylindrical section as well. This higher production rate is fueled by the influx of energetic electrons bombarding the background gas.

\section{Conclusions}

The thruster plume and discharge chamber plasma of a $5 \mathrm{~kW}$ test-bed thruster were investigated. The thruster plume was investigated using Faraday and Langmuir probes. The ratio of the average beam current density to the peak beam current density increased only slightly with increasing thruster power. Beam divergence measurements revealed that the beam divergence half-angle was fairly narrow, with $90 \%$ of the beam included within a $25^{\circ}$ half-angle. It was also found that the radial electric field component in the plume, as inferred from centerline plume measurements, is not capable of imparting significant off-axis energy to those ions born on centerline. Plasma measurements in the thruster plume were also used to estimate low energy ion production due to charge-exchange and electron bombardment ionization. In all cases investigated in this work, charge-exchange dominated the low energy ion production in the plume.

Discharge plasma measurements at the anode were used to estimate the upper limit of electron flux collected between cusps. This upper limit suggests that no more than $30 \%$ of the discharge current may be attributed to electrons flowing to the anode between cusps. It was also found that the majority of both ion and electron collection between cusps occurred in the cylindrical section. This finding suggests that the discharge may be localized in the cylindrical section of the thruster. Additionally, it was found that the electron temperature was on average $3 \mathrm{eV}$ higher in the cylindrical section as compared with the conic section. This finding suggests that the thermalization rate of primary electrons in the cylindrical section may be higher than in the conical section of the thruster. The thermalization of primary electrons in the cylindrical section may be enhanced, in part, due to electron confinement associated with the negatively biased screen grid electrode.

\section{References}

${ }^{1}$ Sovey, J.S. and Rawlin, V.K, "A Synopsis of Ion Propulsion Development Projects in the United States: SERT 1 to Deep Space 1," AIAA Paper 99 2270 , June 1999.

${ }^{2}$ Polk, J.E., Anderson, J.R., and Brophy, J.R., "An Overview of the Results from an 8200 Hour Wear Test of the NSTAR Ion Thruster," AIAA Paper 99-2446, June 1999.

${ }^{3}$ Myers, R. M., Pencil, E. J., Rawlin, V.K, and Oden, K., "NSTAR Ion Thruster Plume Impacts Assessment," AlAA Paper 95-2825, July 1995.

${ }^{4}$ Soulas, G.C., Foster, J.E., and Patterson, M.J., "Performance of Titanium Optics on a NASA 30 cm Ion Thruster," AIAA Paper 2000-3814, July 2000.

${ }^{5}$ Christensen, J.A., et al, " Design and Fabrication of a Flight Model $2.3 \mathrm{~kW}$ Ion Thruster for the Deep Space 1 Mission," AIAA Paper 983327, July 1998.

${ }^{6}$ Sovey, J.S., et al, "Development of an Ion Thruster and Power Processor for New Millenium's Deep Space 1 Mission," AIAA paper 97-2778, December 1997.

${ }^{7}$ Hopkins, M.B., "Electrical Diagnostics in Radio Frequency Discharges," $14^{\text {th }}$ International Vacuum Congress, Birmingham, 1998.

${ }^{8}$ Baragiola, R.A., Alonso, E.V., Ferron, J. and Oliva-Florio, A. "Ion-Induced Electron Emission from Clean Metals, "Surface Science, vol. 90 , 1979, pp. 240-255.

${ }^{9}$ Carruth, M.R., " A Review of Studies on Ion Thruster Beam and Charge Exchange Elasmas," AIAA Paper 82-1944, November 1982.

${ }^{10}$ Kaufman, H.R. and Robinsion, R.S., Operation of Broad Beam Ion Sources, Commonwealth Scientific Corporation:Alexandria, 1984, pp. 173179.

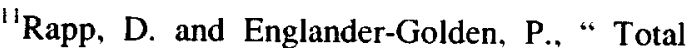
Cross Sections for Ionization and Attachment in Gases by Electron Impact. I. Positive Ionization", Journal of Chemical Physics, vol. 43, September 1965, pp. 1464-1479.

${ }^{12}$ Rapp, D. and Francis, W.E., "Charge Exchange between Gaseous Ions and Atoms," Journal of Chemical Physics, vol. 37, no. 11, December 1962. pp. 2631-2654.

${ }^{13}$ Poeschel, R.L., "Development of Advanced Inert-Gas Ion Thrusters," NASA CR 168206. June 1980.

${ }^{14}$ Kaufman, H.R., Robinson, R., and Frisa, L.E., "Ion Flow Experiments in a Multipole Discharge Chamber," AIAA Journal, vol. 22, no. 11 , November 1984 , pp. 1544-1549. 
${ }^{15}$ Foster, J. and Patterson, M.J., "Internal Plasma Properties and Enhanced Performance of an $8-\mathrm{cm}$ Ion Thruster Discharge," IEPC Paper 99-159, Oct. 1999.

${ }^{16}$ Yoshihiro, A., and Hamantani, C., "Reduction of Plasma Loss to Discharge Chamber Walls in a Ring-Cusp Ion Thruster," Journal of Propulsion and Power, vol. 3, no. 1, January 1987, pp. 90-91.
${ }^{17}$ Hayakawa, Y., Miyazaki. K., and Kitamura, S., "Measurement of Electron Energy Distributions in a $14 \mathrm{~cm}$ Diameter Ring Cusp Ion Thruster," AIAA Paper 89-2715, July 1989.

Table I. Thruster Operating Conditions

\begin{tabular}{|cccccc}
\hline $\begin{array}{c}\text { Input Power, } \\
\mathrm{kW}\end{array}$ & $\begin{array}{c}\text { Discharge } \\
\text { Current, A }\end{array}$ & $\begin{array}{c}\text { Discharge } \\
\text { Power, W }\end{array}$ & $\begin{array}{c}\text { Beam } \\
\text { Voltage, V }\end{array}$ & $\begin{array}{c}\text { Accelerator } \\
\text { Voltage, V }\end{array}$ & $\begin{array}{c}\text { Beam } \\
\text { Current, A }\end{array}$ \\
\hline 0.5 & 4.6 & 121 & 650 & -150 & 0.51 \\
1.0 & 6.2 & 162 & 1100 & -150 & 0.71 \\
1.4 & 8.4 & 203 & 1100 & -180 & 1.10 \\
1.7 & 9.2 & 228 & 1100 & -180 & 1.30 \\
1.9 & 10.2 & 253 & 1100 & -180 & 1.49 \\
2.3 & 12.6 & 301 & 1100 & -180 & 1.76 \\
3.0 & 12.2 & 294 & 1500 & -250 & 1.76 \\
4.6 & 19.6 & 464 & 1500 & -250 & 2.70 \\
\hline
\end{tabular}

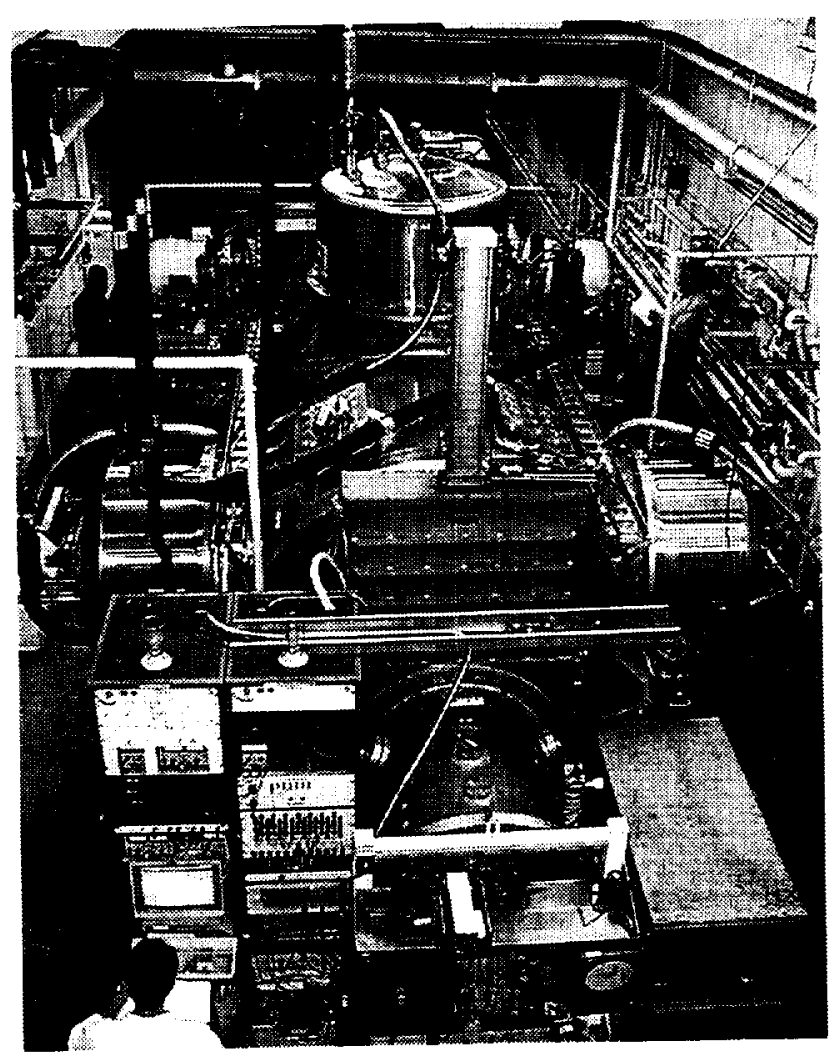

Figure 1. Vacuum Facility 11. 


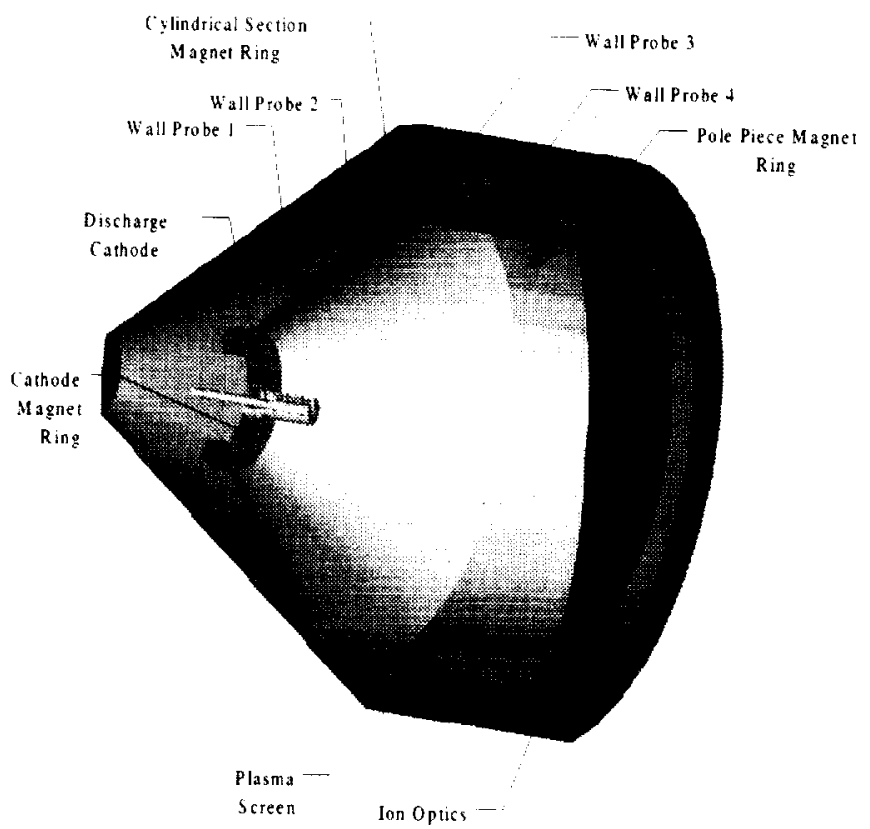

Figure 2. Cutaway of the thruster revealing internal diagnostics, optics, and discharge cathode.

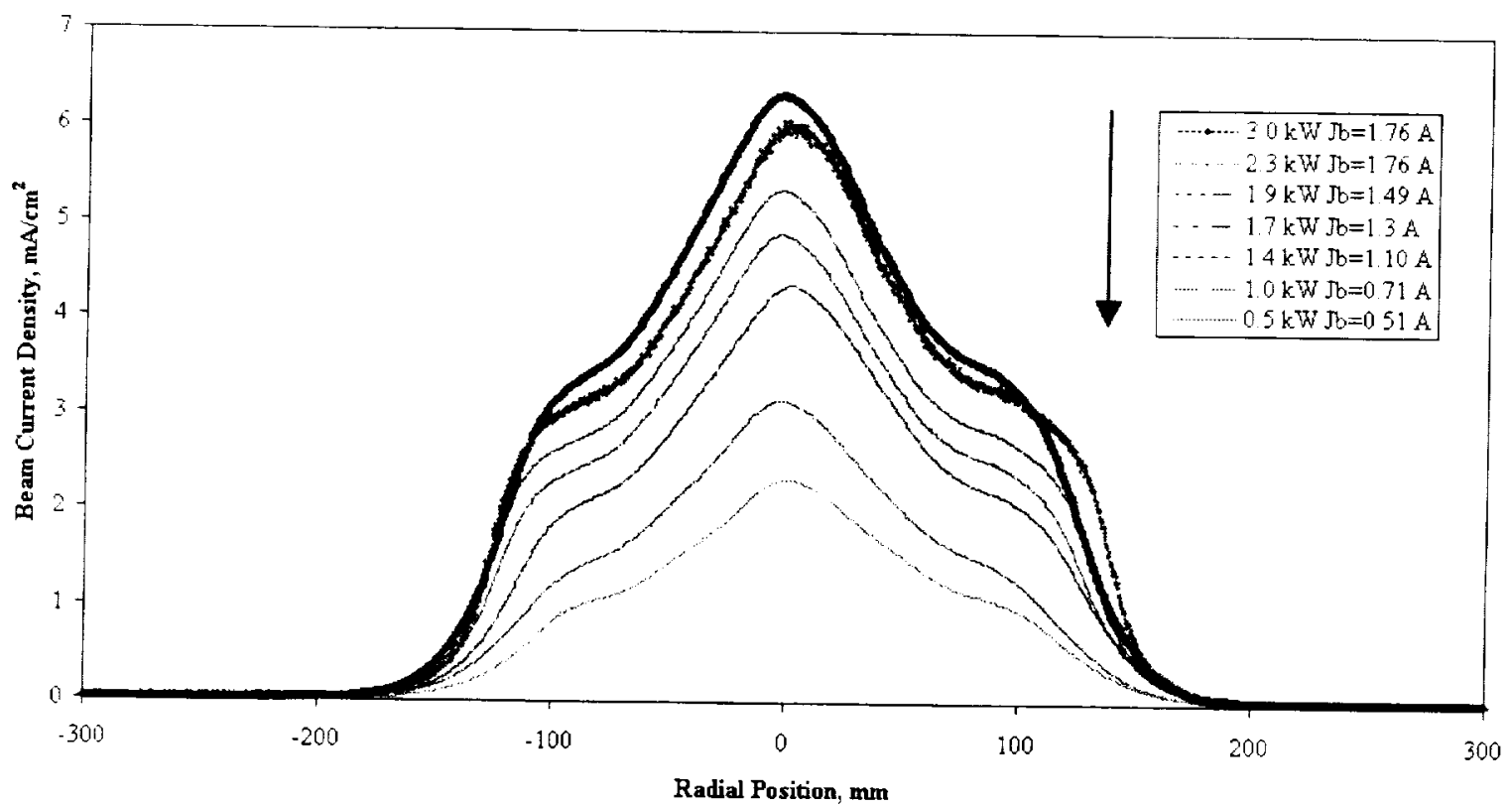

Figure 3. Beam current density profiles at various input thruster powers at $49 \mathrm{~mm}$ downstream of optics. 


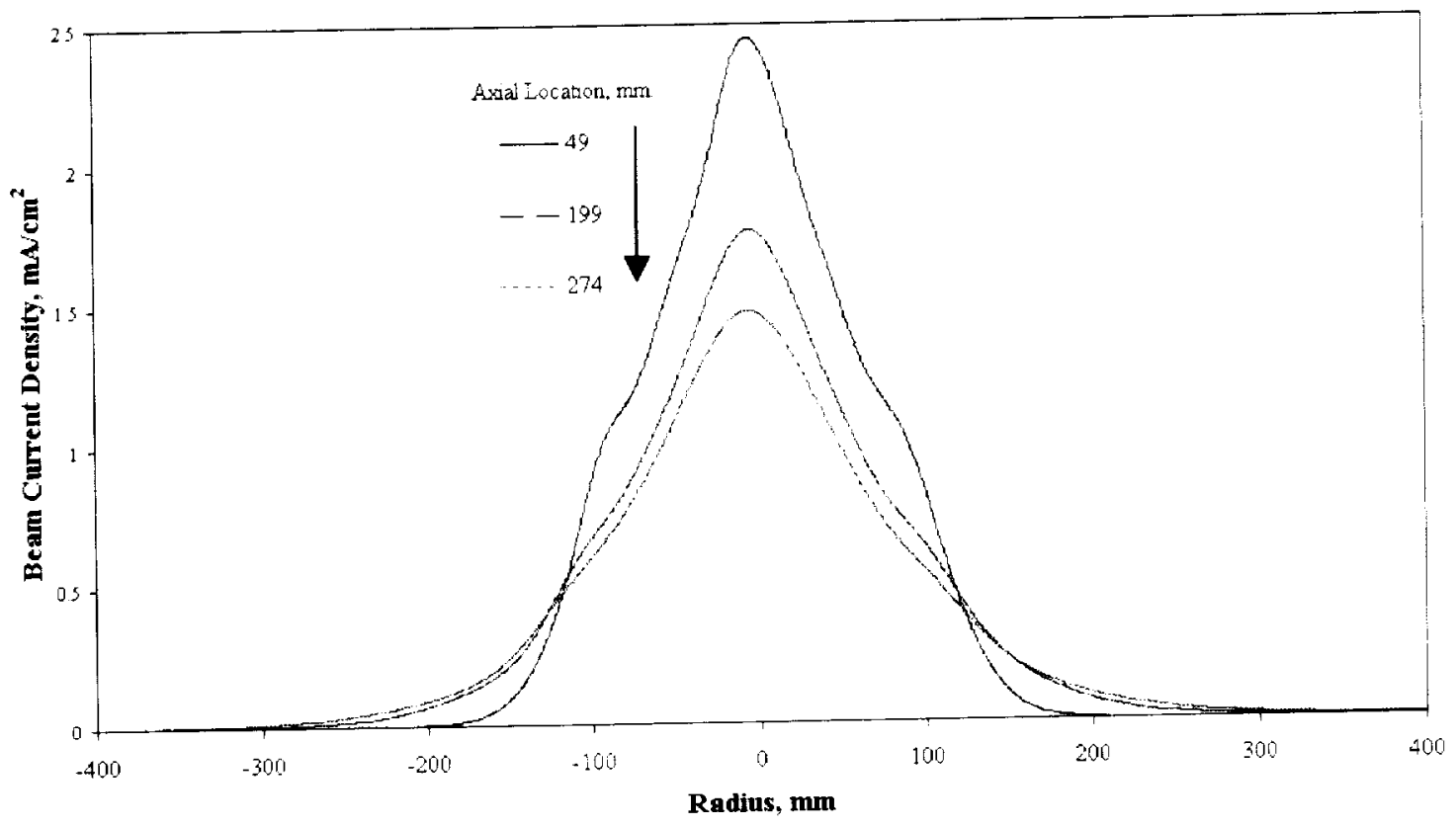

Figure 4. Variations in the plume profile with axial distance at a thruster input power of $0.5 \mathrm{~kW}$.

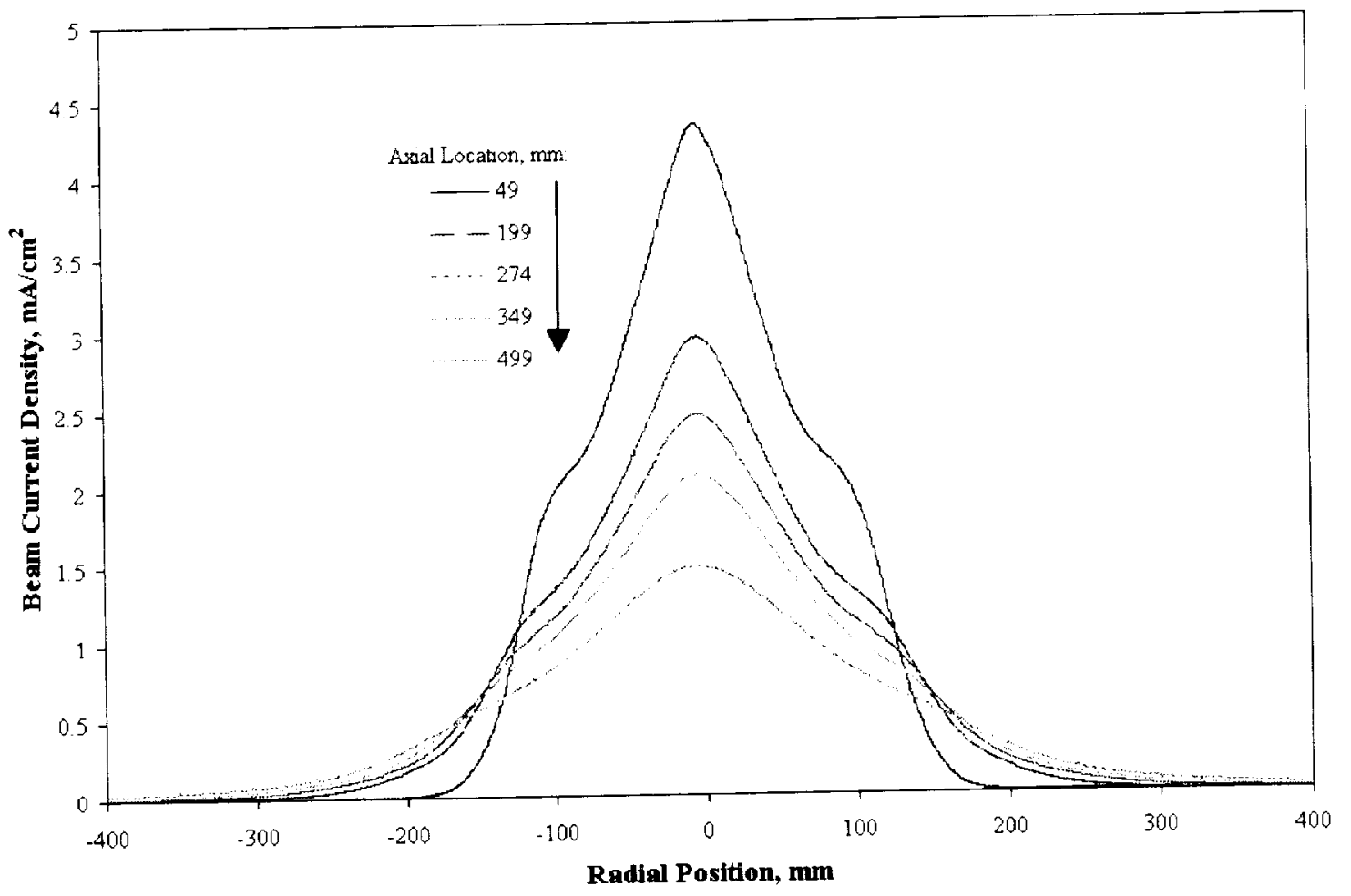

Figure 5. Variation in plume profile with axial distance at a thruster input power of $1.4 \mathrm{~kW}$. 


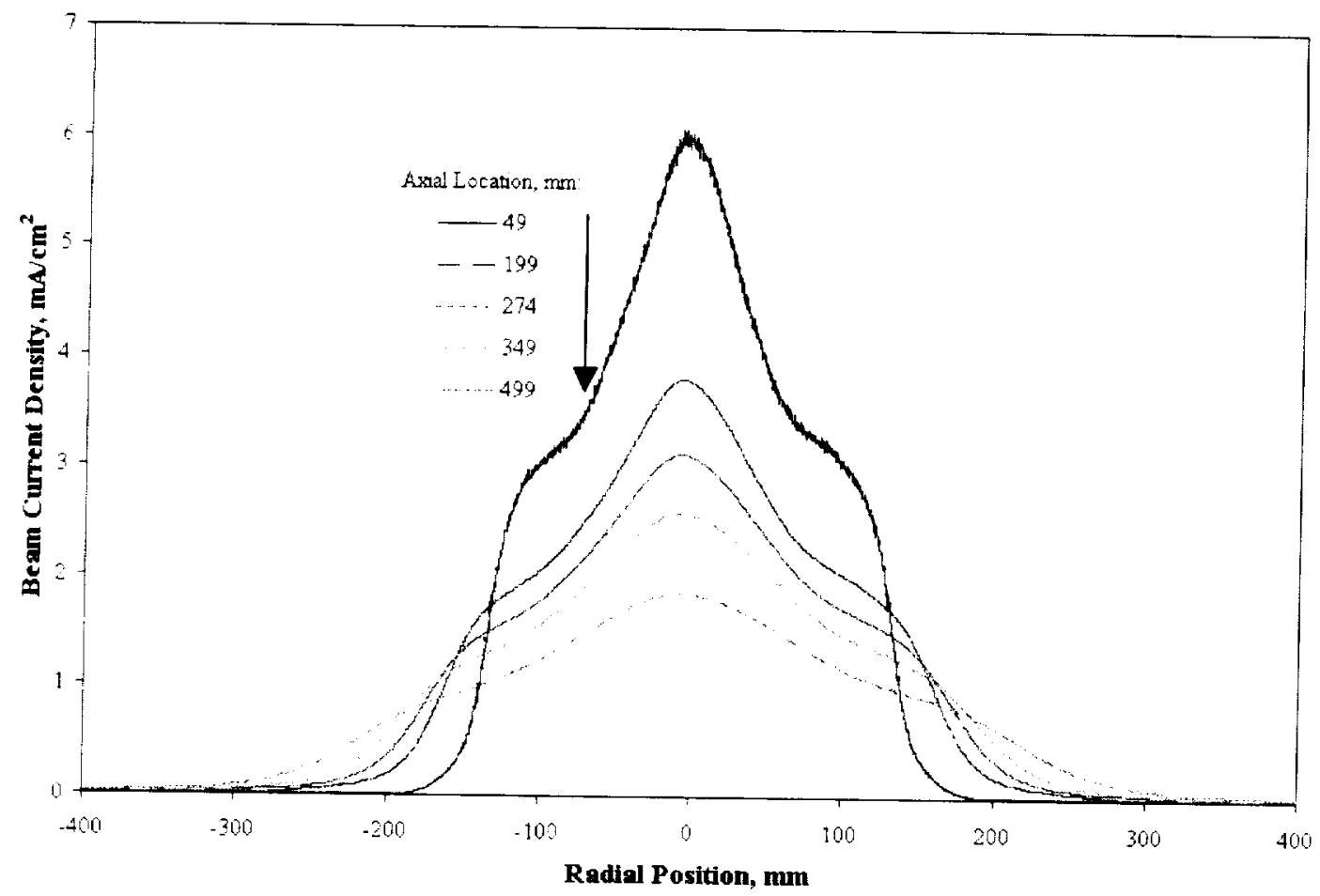

Figure 6. Variation in plume profile with axial distance at a thruster input power of $2.3 \mathrm{~kW}$.

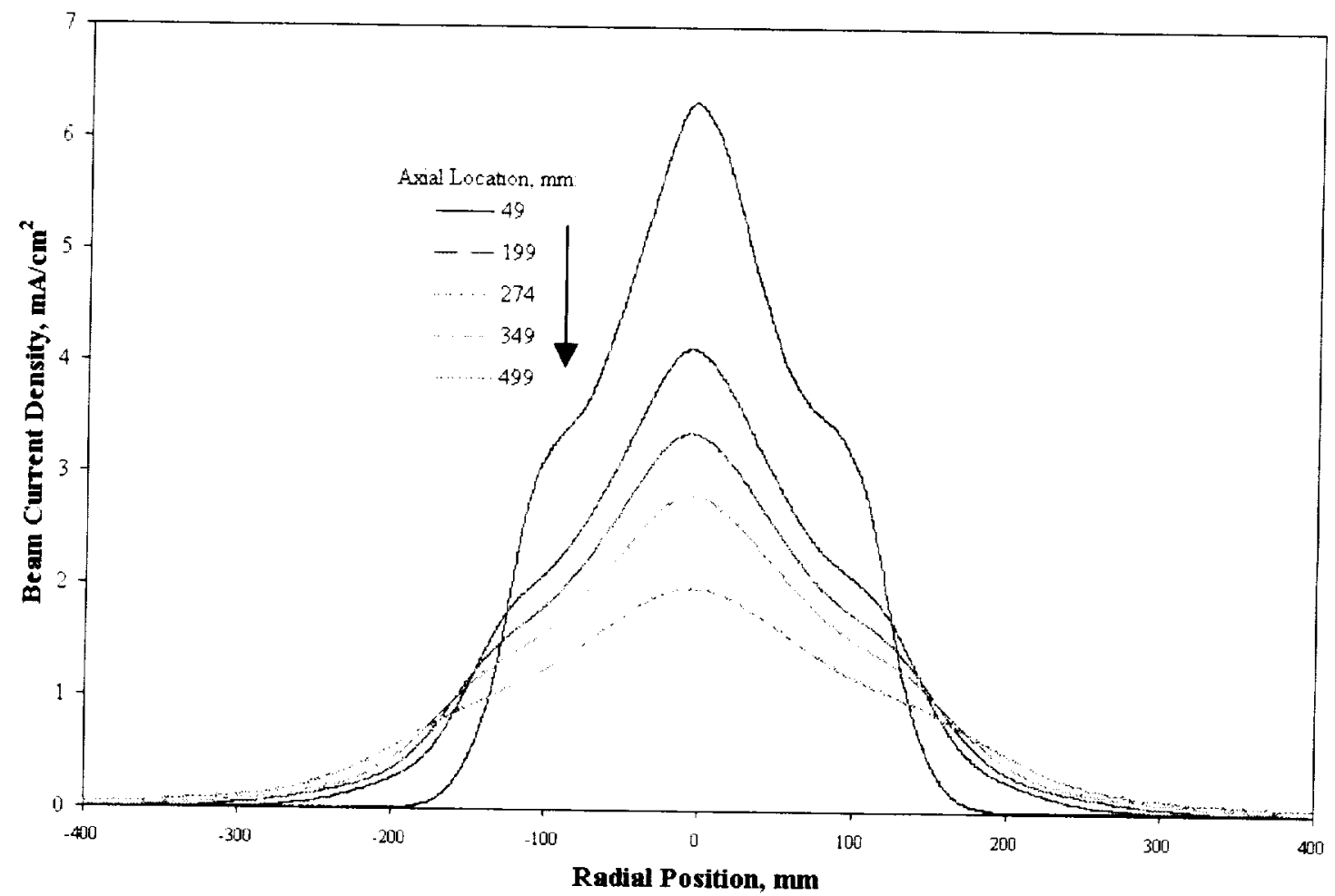

Figure 7. Variation in plume profile with axial distance at a thruster input power of $3.0 \mathrm{~kW}$. 


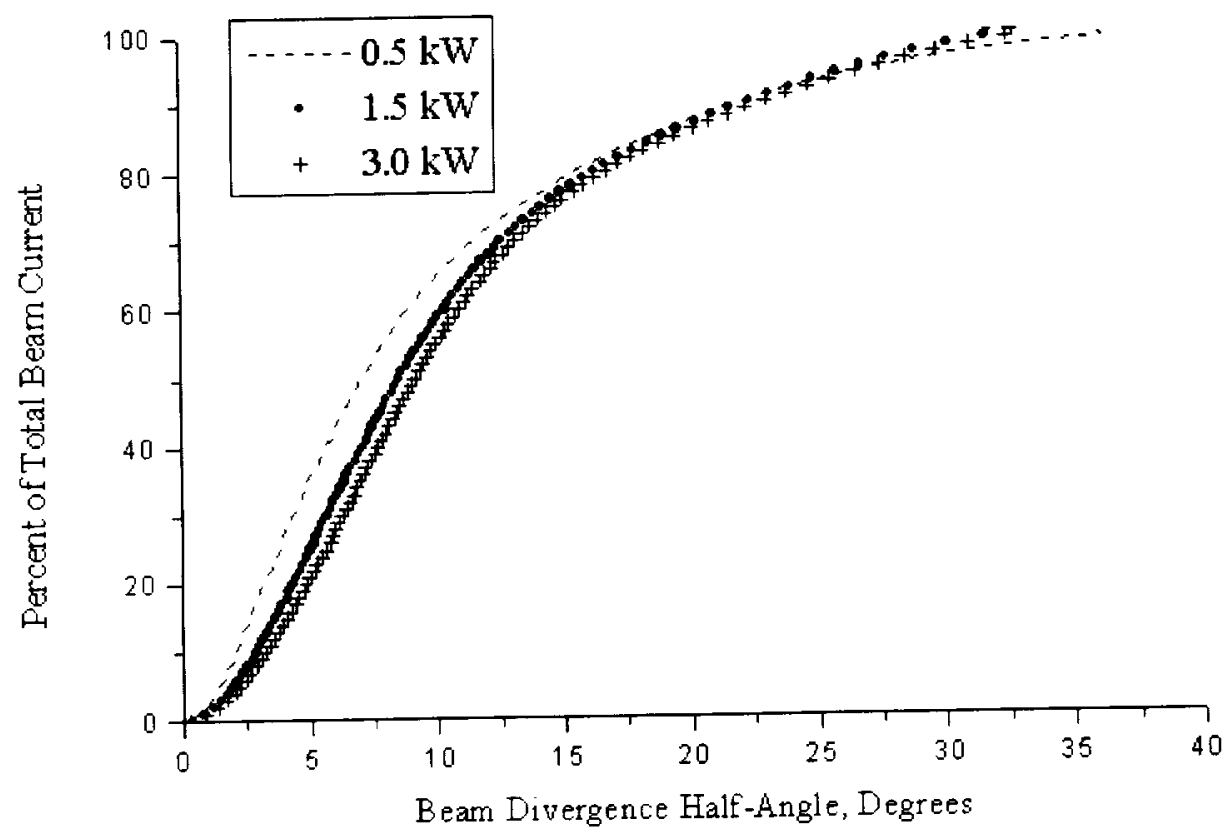

Figure 8. Beam divergence as a function of operating condition.

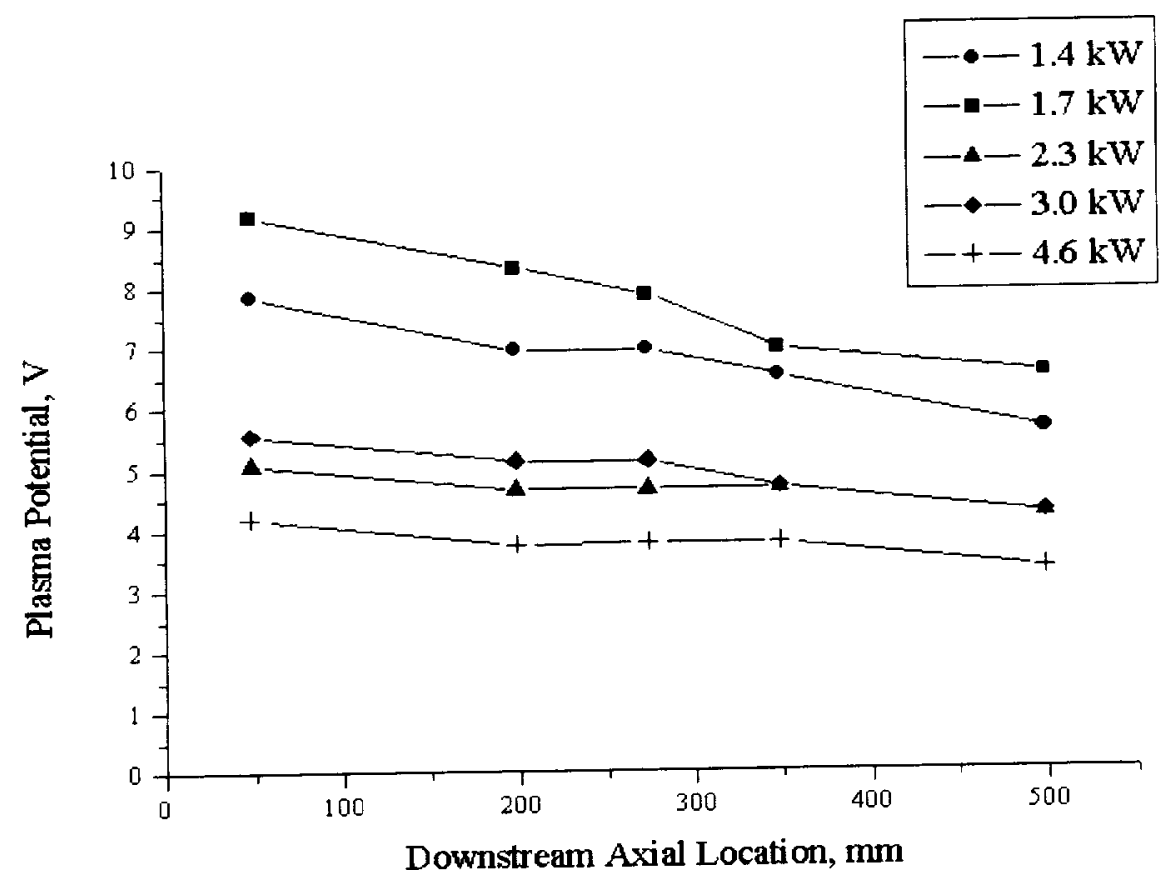

Figure 9. Axial plasma potential profiles taken on centerline downstream of ion optics. 


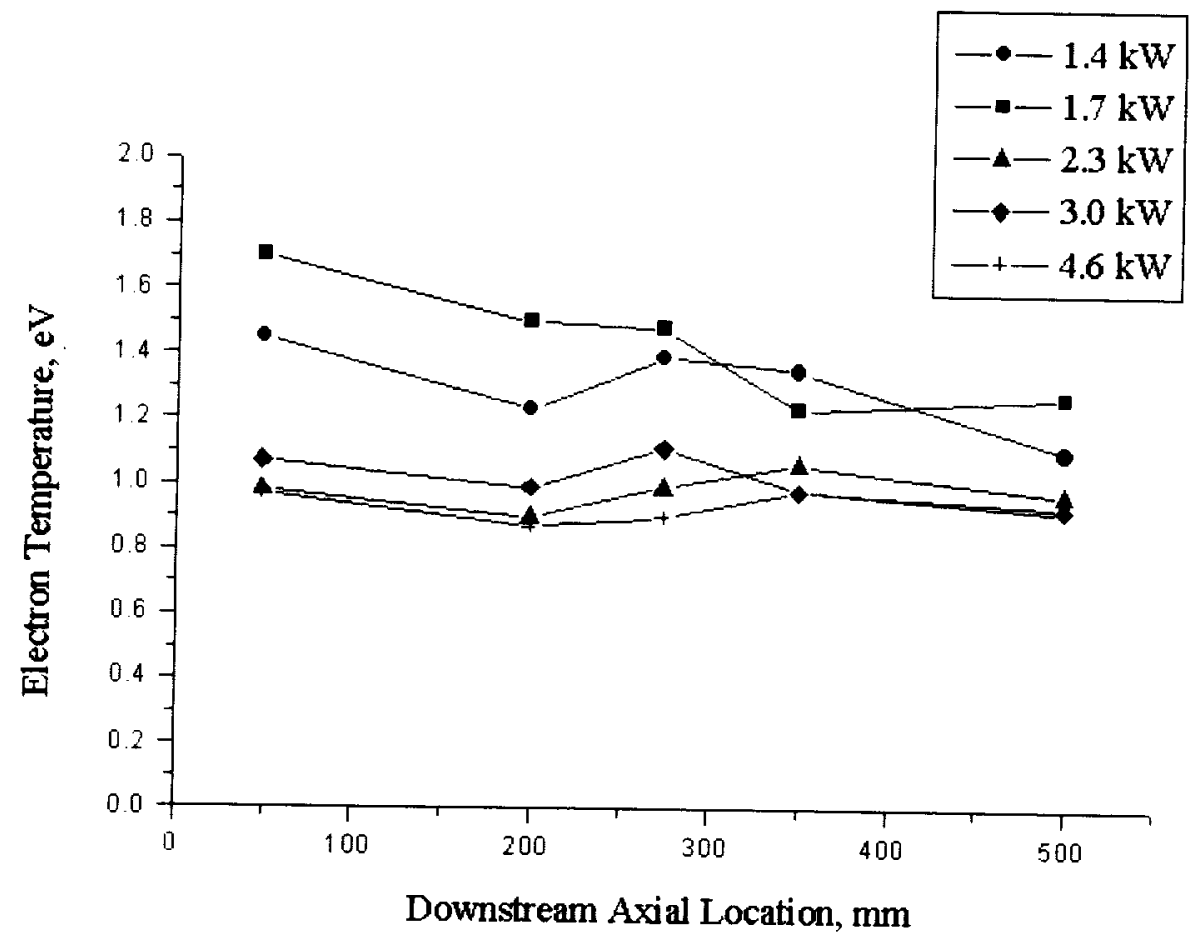

Figure 10. Axial electron temperature profiles taken with a Langmuir probe on the ion optics centerline.

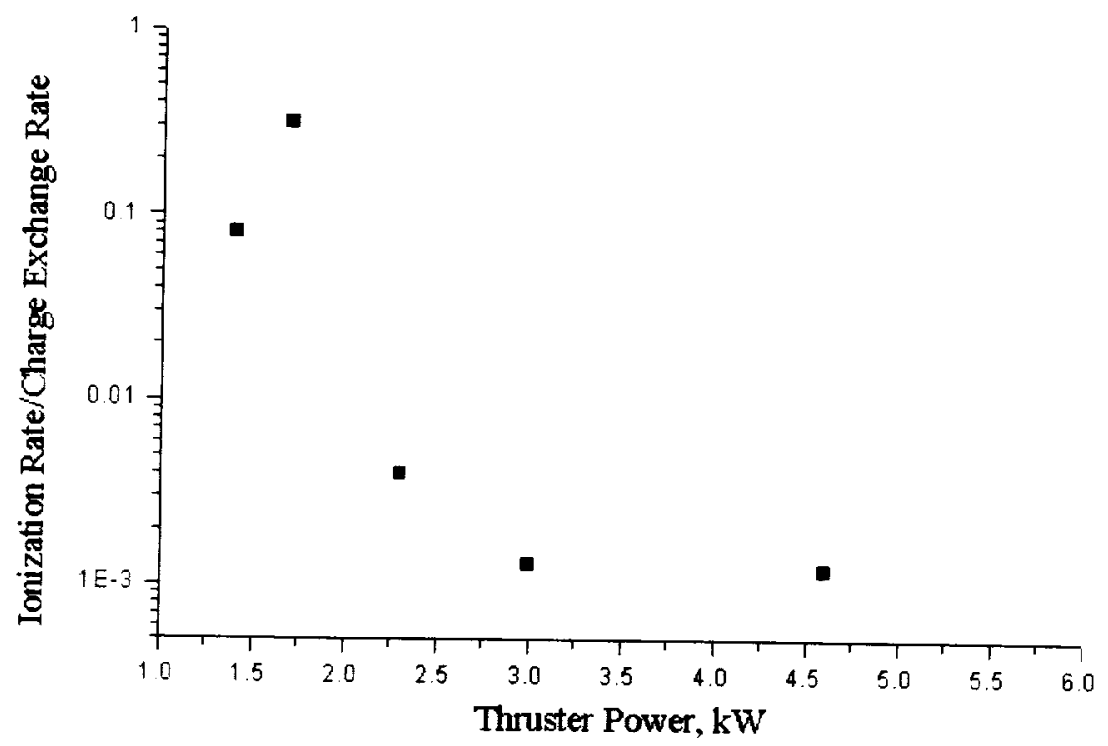

Figure 11. Ratio of ionization rate to charge exchange rate as a function of input power. 


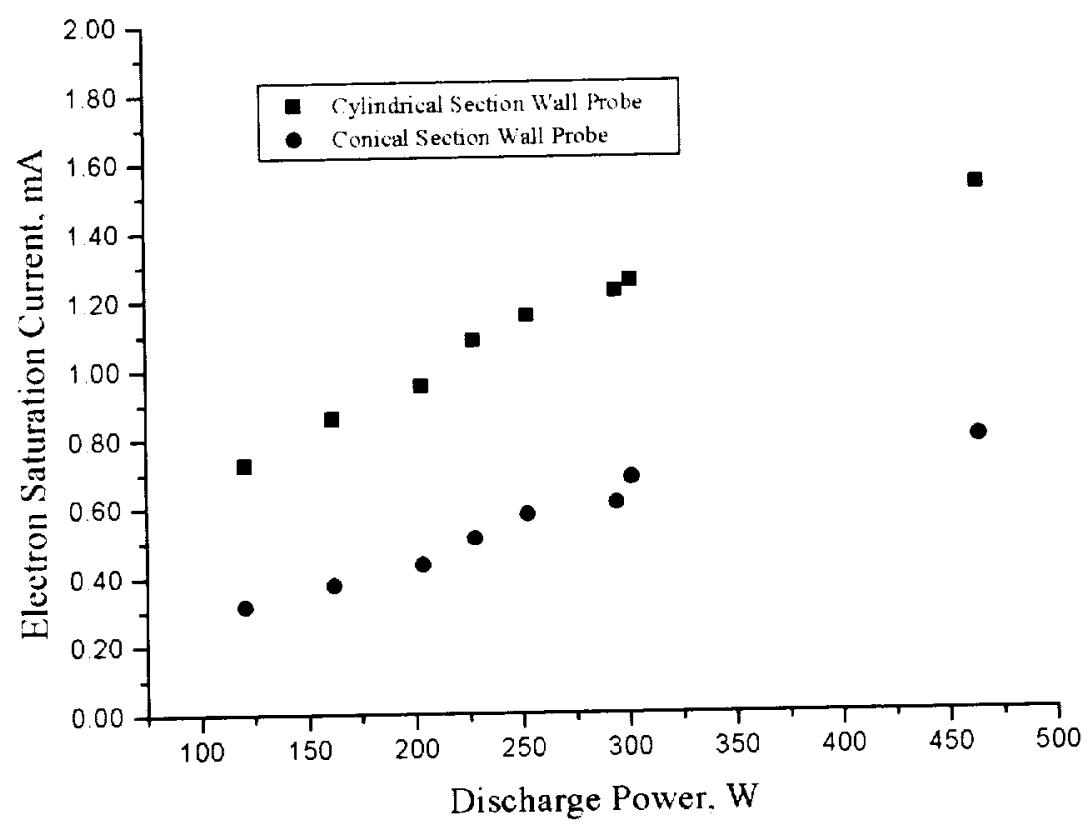

Figure 12. Variation in electron saturation current collected at anode wall probes as a function of discharge power.

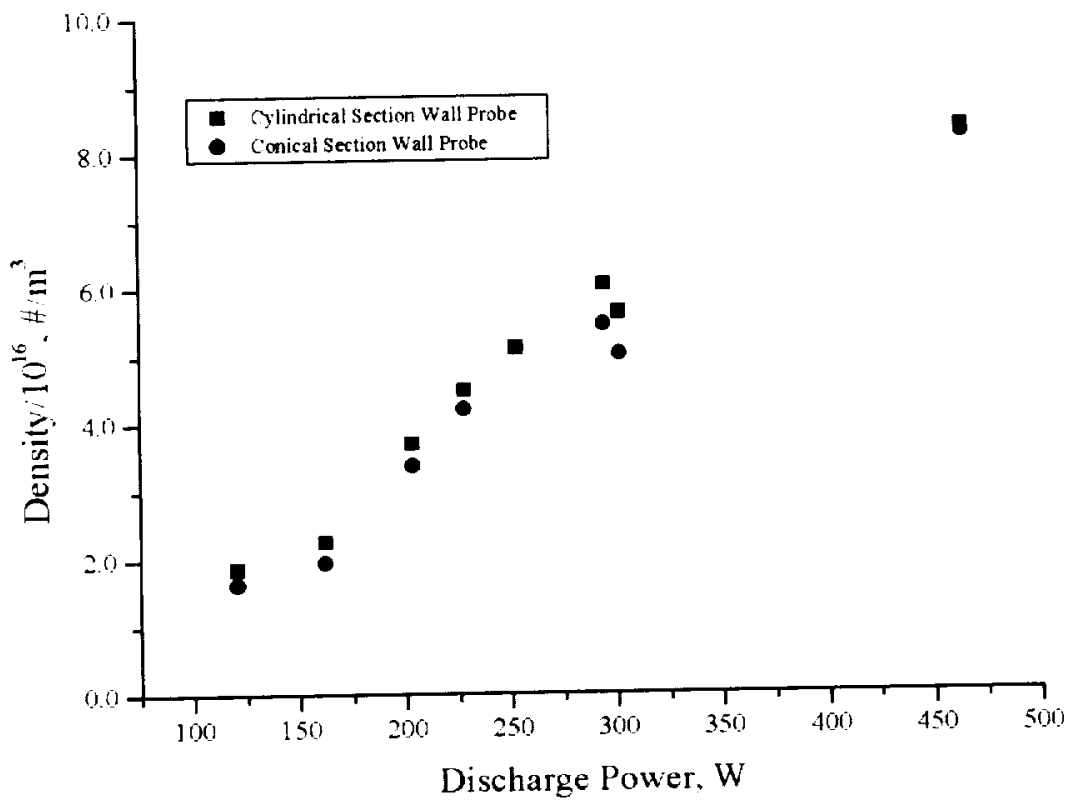

Figure 13. Ion density measured at anode wall probes as a function of discharge power. 


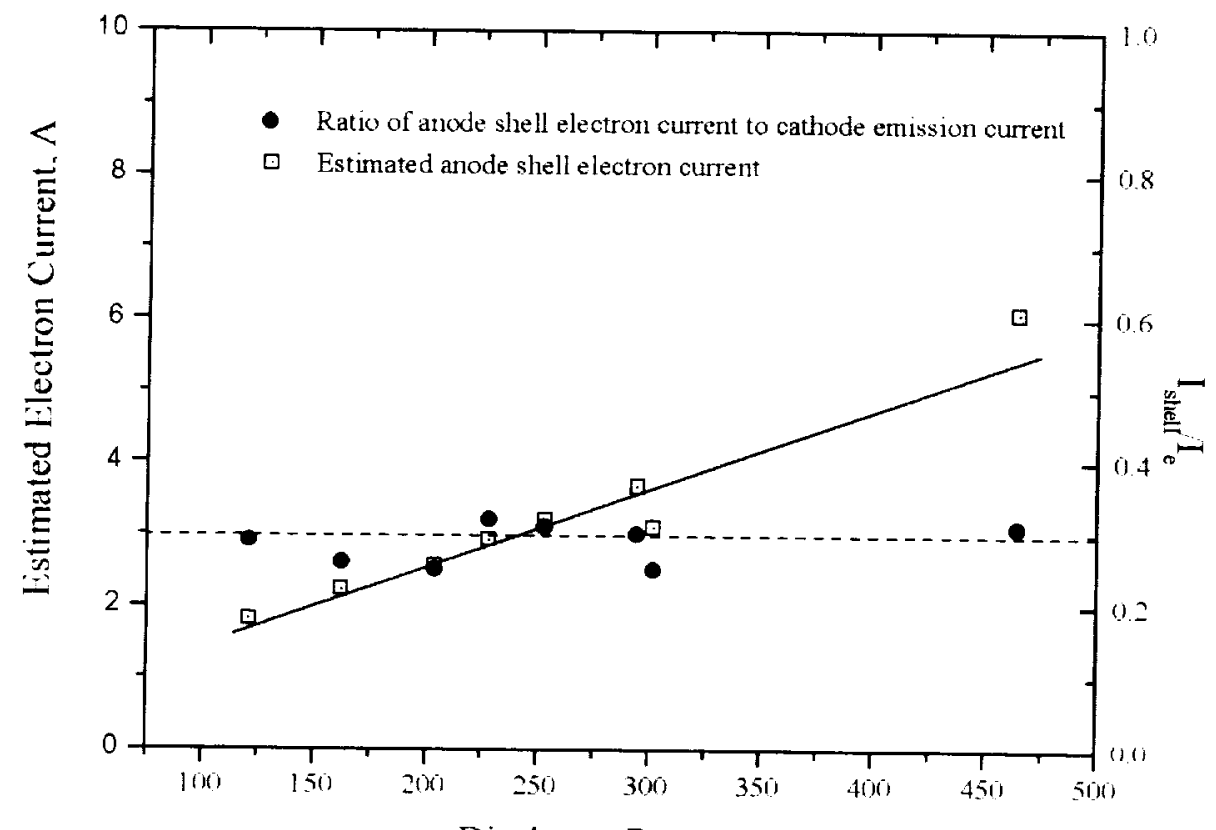

Discharge Power, A

Figure 14. Variations in electron current collected at the anode shell with discharge power.

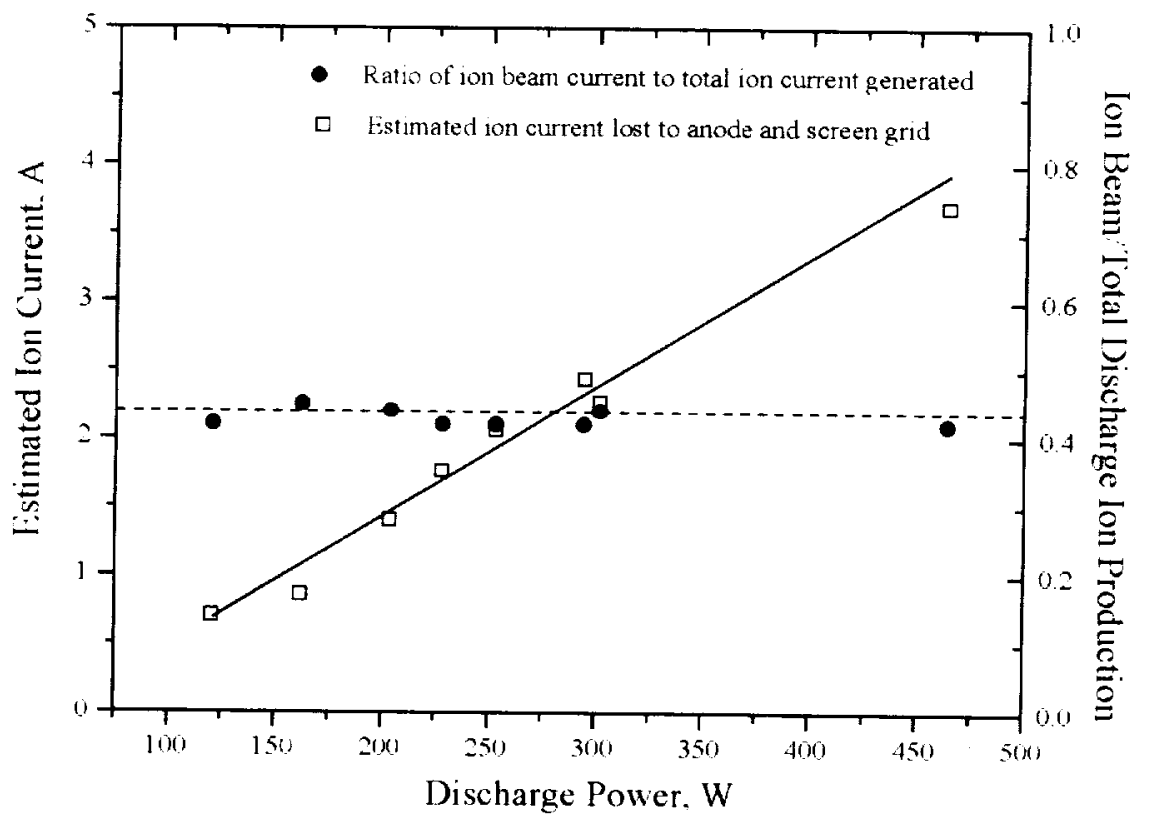

Figure 15. Variations in ion current collection with discharge power. 


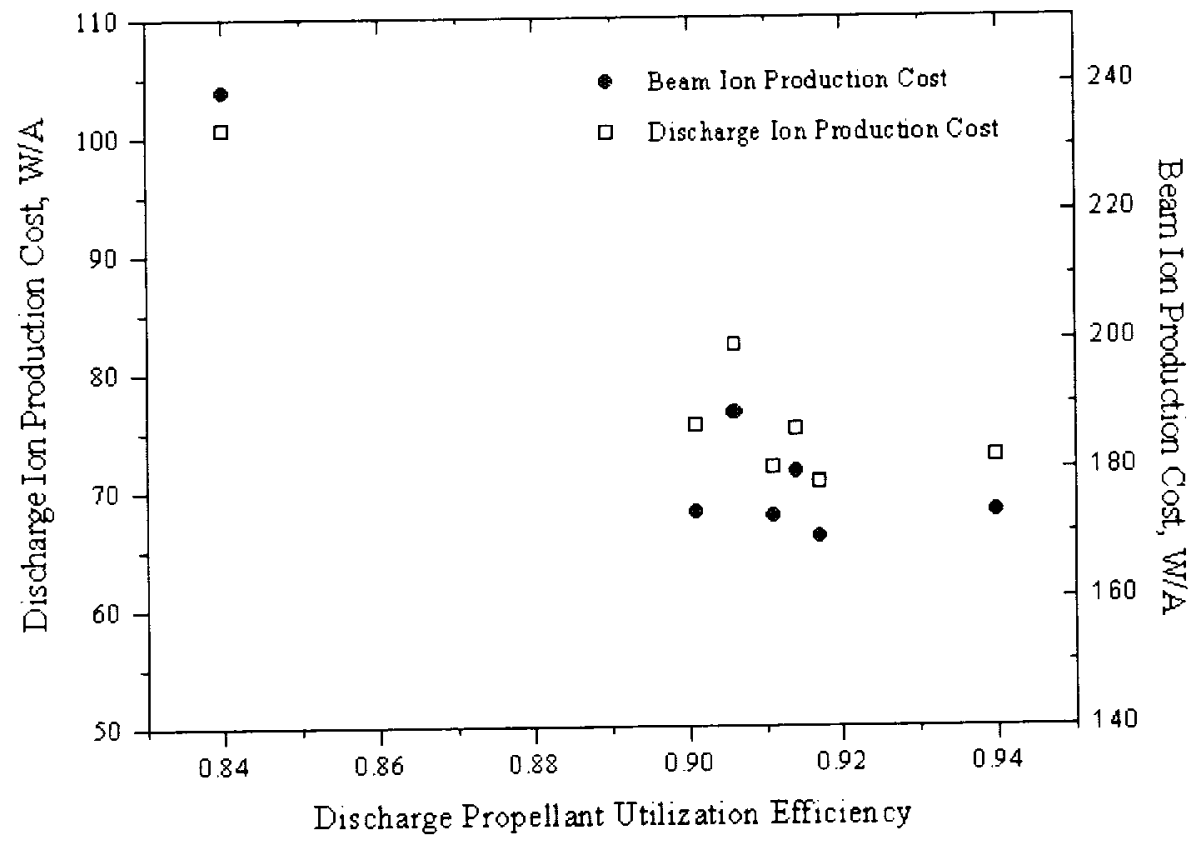

Figure 16. Discharge and beam ion production costs as a function of discharge propellant utilization efficiency.

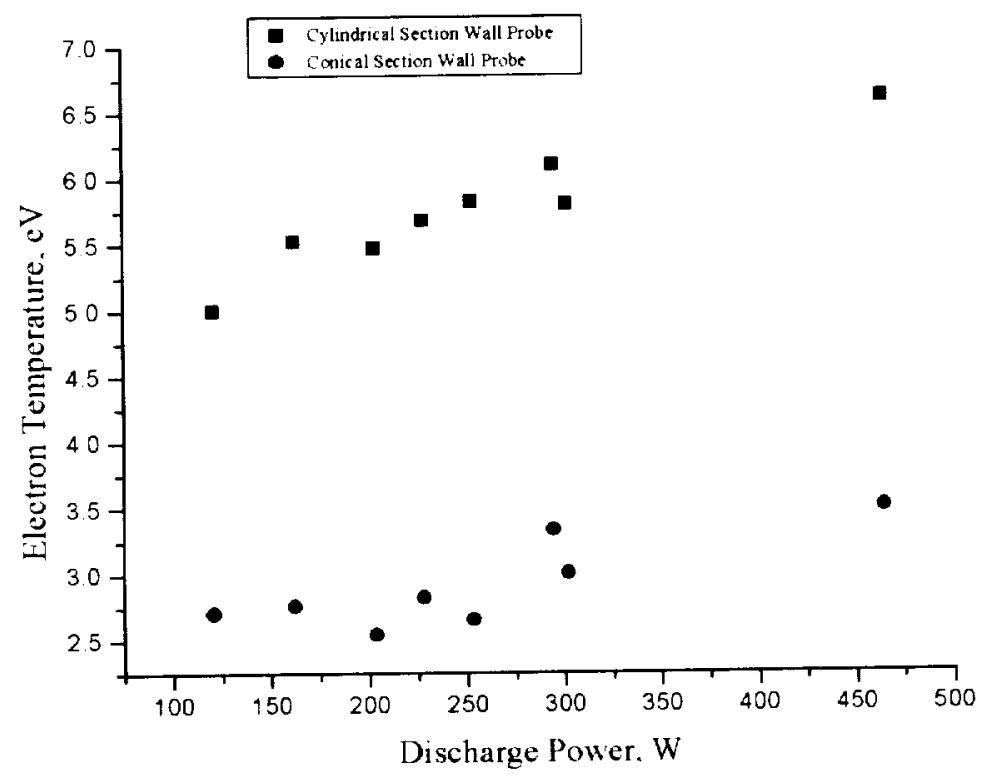

Figure 17. Internal electron temperature variations measured at the wall probes as a function of discharge power. 


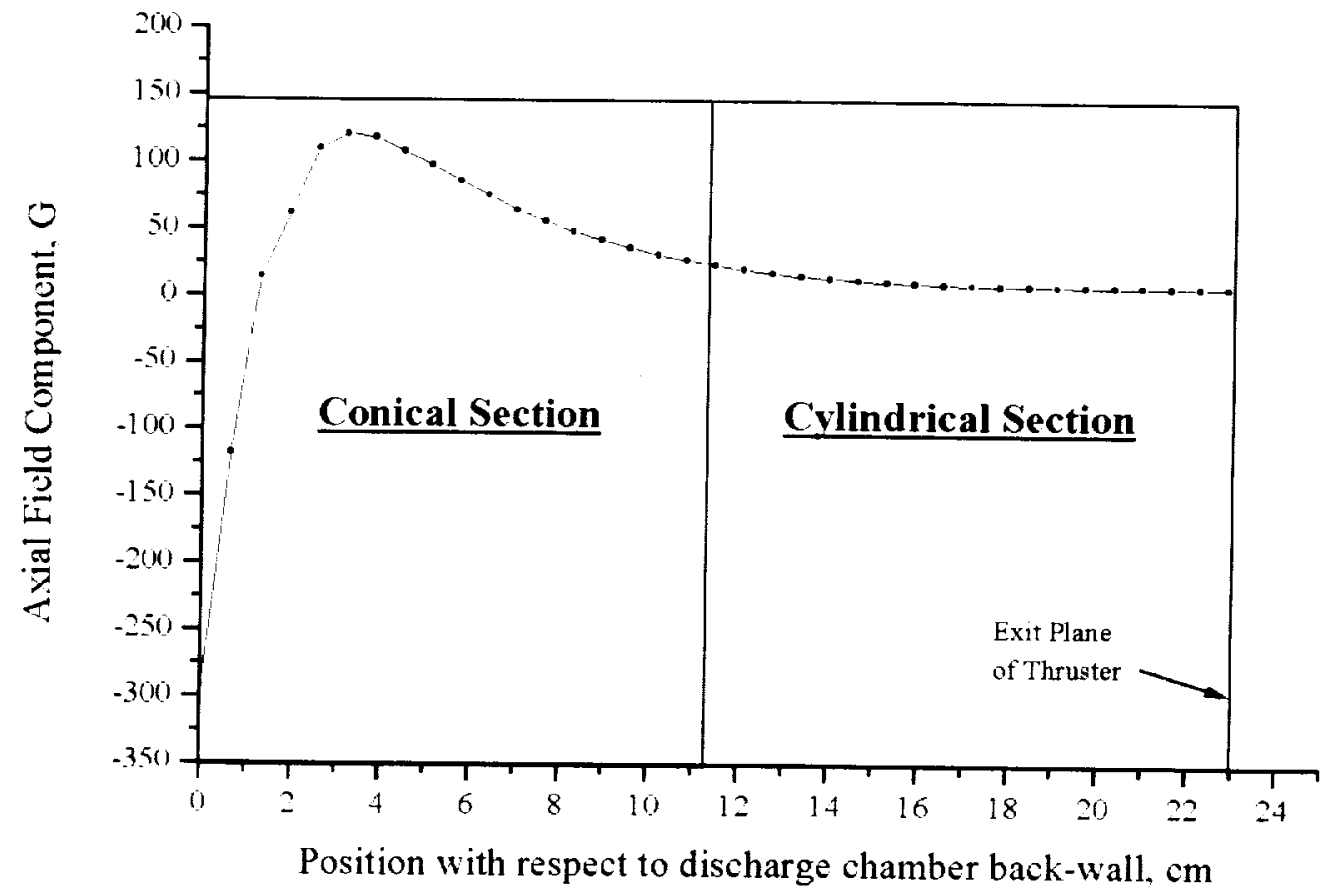

Figure 18. Variations in the axial magnetic field as a function of position downstream of the discharge chamber back-wall. 


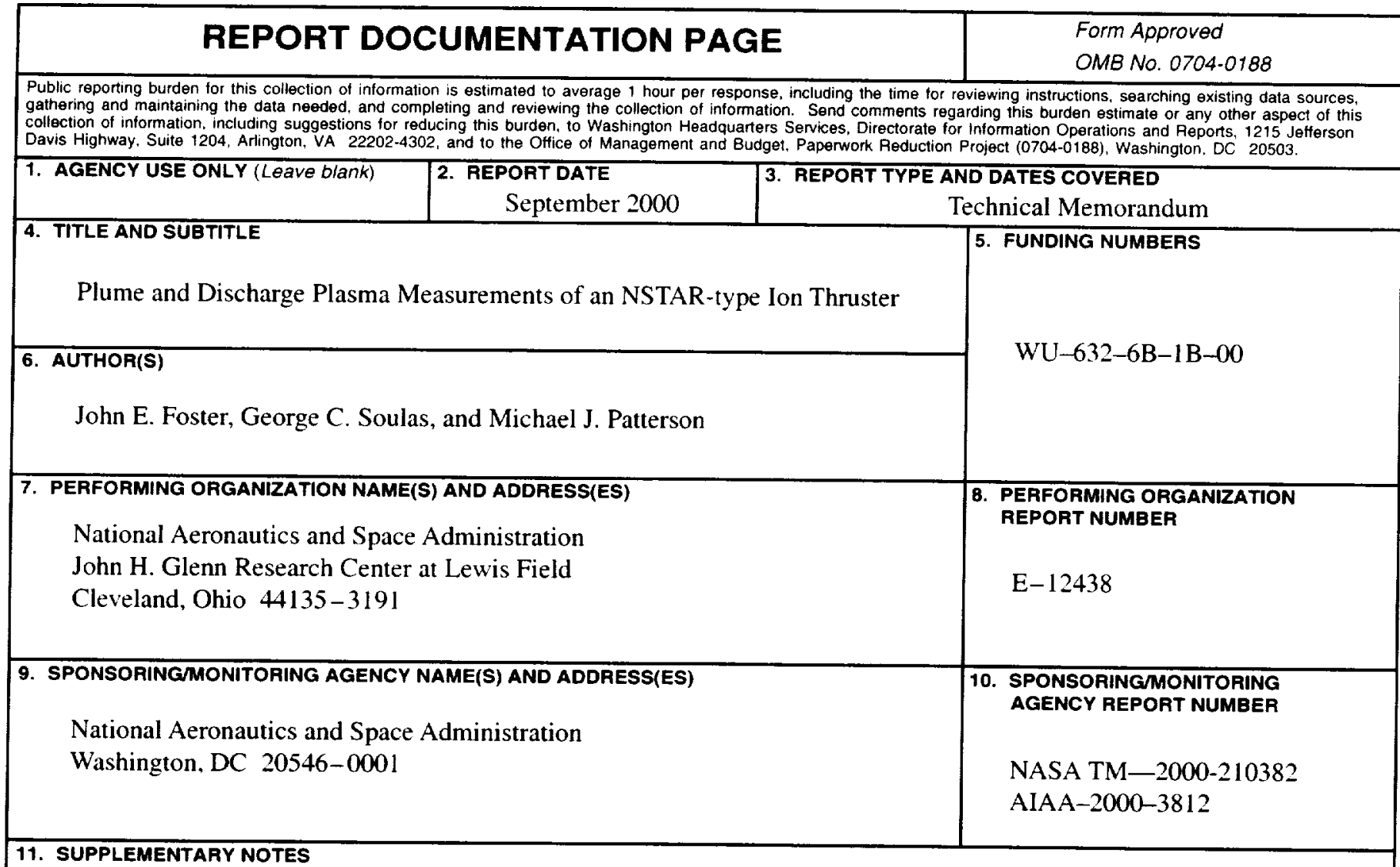

Prepared for the 36th Joint Propulsion Conference and Exhibit sponsored by the American Institute of Aeronautics and Astronautics, Huntsville, Alabama, July 16-19, 2000. Responsible person, John E. Foster, organization code 5430, (216) 433-6131.

12a. DISTRIBUTION/AVAILABILITY STATEMENT

12b. DISTRIBUTION CODE

Unclassified - Unlimited

Subject Categories: 20 and 75

Distribution: Nonstandard

This publication is available from the NASA Center for AeroSpace Information. (301) $621-0390$.

13. ABSTRACT (Maximum 200 words)

The success of the NASA Deep Space 1 spacecraft has demonstrated that ion propulsion is a viable option for deep space science missions. More aggressive missions such as Comet Nuclear Sample Return and Europa lander will require higher power, higher propellant throughput and longer thruster lifetime than the NASA Solar Electric Propulsion Technology Application Readiness (NSTAR) engine. Presented here are thruster plume and discharge plasma measurements of an NSTAR-type thruster operated from $0.5 \mathrm{~kW}$ to $5 \mathrm{~kW}$. From Faraday plume sweeps, beam divergence was determined. From Langmuir probe plume measurements on centerline, low energy ion production on axis due to chargeexchange and direct ionization was assessed. Additionally, plume plasma potential measurements made on axis were used to determine the upper energy limits at which ions created on centerline could be radially accelerated. Wall probes flush-mounted to the thruster discharge chamber anode were used to assess plasma conditions. Langmuir probe measurements at the wall indicated significant differences in the electron temperature in the cylindrical and conical sections of the discharge chamber.

14. SUBJECT TERMS

Ion thruster: Ion plume; Faraday probe; Plasma; Charge-exchange; Electron temperature

\begin{tabular}{|c|c|c|}
\hline $\begin{array}{c}\text { 17. SECURITY CLASSIFICATION } \\
\text { OF REPORT } \\
\text { Unclassified }\end{array}$ & $\begin{array}{c}\text { 18. SECURITY CLASSIFICATION } \\
\text { OF THIS PAGE } \\
\text { Unclassified }\end{array}$ & $\begin{array}{c}\text { 19. SECURITY CLASSIFICATION } \\
\text { OF ABSTRACT } \\
\text { Unclassified }\end{array}$ \\
\hline
\end{tabular}


,

,

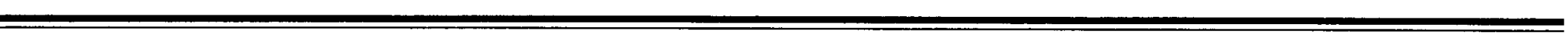

